\title{
Clinical Update on the Use of Moxifloxacin in the Treatment of Community-Acquired Complicated Intraabdominal Infections
}

\author{
William Cheadle,, James T. Lee, Lena M. Napolitano,, ${ }^{4,5}$ and Ronald Lee Nichols ${ }^{6}$
}

\begin{abstract}
Background: Community-acquired complicated intraabdominal infections (cIAIs) present problems for clinicians and have substantial impact on hospital resources. Because of the polymicrobial nature of these infections, successful management of cIAIs depends on timely and appropriate use of antisepsis and antiinfective strategies. Methods: The literature pertinent to this article was reviewed.

Results: The Surgical Infection Society and the Infectious Disease Society of America guidelines recommend a variety of single and combined antimicrobial therapies, including fluoroquinolone therapy, for prophylactic and definitive treatment of cIAIs with different severities. Moxifloxacin, a fluoroquinolone, demonstrates a broad spectrum of antimicrobial (including anaerobic) activity, good tissue penetration into the gastrointestinal tract, and a good tolerability profile. Clinical data also have demonstrated that moxifloxacin is effective as monotherapy for patients with cIAIs. This review identifies the clinical issues impacting antimicrobial selection in cIAI and discusses data on the role of moxifloxacin in light of the current guidelines for management of these patients.

Conclusion: Moxifloxacin provides clinicians with a convenient monotherapy option for the treatment of mildto-moderate cIAIs.
\end{abstract}

$\mathrm{C}$ OMMUNITY-ACQUIRED complicated intraabdominal infections (cIAIs) are encountered frequently in clinical practice and are associated with substantial morbidity and mortality [1]. Mortality rates between $30 \%$ and $50 \%$ are not uncommon in patients with severe cIAIs [2]. To manage these infections, substantial hospital resources are required [1]. Rapid diagnosis, coupled with the timely use of appropriate antisepsis and antiinfective strategies, may improve outcomes by preventing death or subsequent infections in many patients [1]. In particular, recent clinical data provide compelling evidence for the important role of fluoroquinolone therapy in treating cIAIs. This review addresses the clinical and bacteriological evidences for the use of moxifloxacin as monotherapy in the treatment of cIAIs.

\section{Intraabdominal Pathophysiology and Infection Classification}

Intraabdominal infections can be classified as uncomplicated or complicated. Uncomplicated infections are defined as infectious processes that involve only a single organ, with no anatomical disruption [3]. These infections are often managed with surgical resection alone, without extensive antibiotic therapy, except for preoperative prophylaxis. On the other hand, cIAIs involve infections that extend beyond the hollow viscus of origin into the peritoneal space. These infections are associated with abscess formation or peritonitis and require operative or percutaneous procedures for source control $[1,4,5]$. Infections with predominantly gram-negative aerobes

\footnotetext{
${ }^{1}$ Department of Surgery, University of Louisville, Louisville, Kentucky.

${ }^{2}$ Research and Development, Veterans Affairs Medical Center, Louisville, Kentucky.

${ }^{3}$ Department of Surgery (Retired), University of Minnesota Medical School, Minneapolis, Minnesota

${ }^{4}$ Acute Care Surgery [Trauma, Burn, Critical Care, Emergency Surgery] and ${ }^{5}$ Department of Surgery, University of Michigan Health Care System, Ann Arbor, Michigan.

${ }^{6}$ Department of Surgery-Emeritus, Tulane School of Medicine, New Orleans, Louisiana.
} 
and gram-positive cocci produce secondary peritonitis, whereas anaerobes are predominantly responsible for the development of abscess [6,7].

Uncomplicated infections typically include acute cholecystitis, acute diverticulitis, and acute appendicitis [3,8]. Complicated infections include localized or diffuse peritonitis, including florid fecal peritonitis and complicated diverticulitis or appendicitis with abscess or perforation [1,8]. Uncomplicated intraabdominal infections may progress to cIAIs depending on the rapidity and appropriateness of treatment [6,7]. Although many intraabdominal infections are acquired following operative procedures or hospital stay, most intraabdominal infections $(80 \%)$ are community-acquired $[1,9]$.

A variety of aerobic and anaerobic pathogens are involved in the pathophysiology of cIAIs, with the prevalent pathogen depending on the origin of the infection [1]. Common pathogens isolated from the stomach, duodenum, biliary system, and proximal small bowel are gram-positive and gramnegative aerobic and facultative organisms. Gram-negative facultative and aerobic organisms with variable density, along with anaerobes (e.g., Bacteroides fragilis), are frequent isolates from the distal small bowel. Colon-derived infections typically present with facultative or obligate anaerobic organisms such as streptococci and enterococci and frequently include Escherichia coli $[1,4,5,10]$ (Table 1). Regardless of the location, cIAIs are usually polymicrobial in nature, with anaerobes being the dominant flora [11,12]. Of the cIAIs encountered, complicated appendicitis and diverticulitis are the most frequent and are predominantly responsible for emergency department visits because of acute abdominal pain.

\section{Appendicitis and Diverticulitis: Common Causes of clAl}

Appendicitis, occurring in $7 \%$ of the population over the course of a lifetime, is one of the most common causes of intraabdominal infections and the most common surgical cause of abdominal pain [13-17]. Because of low suspicion in patients presenting with symptoms, missed diagnosis is a fairly common concern, with rates as high as $20 \%-40 \%$ reported in some patient populations. The use of diagnostic algorithms has been observed to reduce these rates to as low as $6 \%$. In some patients, atypical presentation with normal

Table 1. Pathogens Encountered in Complicated INTRAABDOMINAL INFECTIONS

\begin{tabular}{ll}
\hline Gram-negative & Gram-positive \\
\hline Aerobic bacteria & \\
Escherichia coli & Streptococcus \\
Klebsiella species & Enterococcus \\
Pseudomonas species & Staphylococcus \\
Enterobacter species & \\
Proteus species & \\
Acinetobacter species & \\
Anaerobic bacteria & \\
Bacteroides species & Peptostreptococcus \\
Fusobacterium & Clostridium \\
Prevotella & Gemella \\
Porphyromonas & \\
\hline
\end{tabular}

Adapted from Blot and De Waele [5] and Solomkin et al. [10]. vital signs, physical examination, or white blood cell counts (10\%-30\%) may hinder diagnosis. Common pathogens seen in appendicitis are E. coli, Klebsiella spp., Enterococci spp., B. fragilis, and Clostridium spp. [18].

Diverticulosis, a precursor of diverticulitis, is an acquired phenomenon primarily seen in populations consuming a lowfiber diet [19-23]. Up to $25 \%$ of people with diverticulosis will ultimately develop an infectious complication, the hallmark of which is presentation of lower quadrant pain. Although most patients present with uncomplicated disease, a high recurrence rate $(33 \%)$ often leads to the development of serious complications. Common offending pathogens include E. coli, Streptococcus spp., B. fragilis, Clostridium spp., and Fusobacterium spp.

\section{Treatment of clAl}

Treatment objectives include controlling the source of infection, eliminating the infecting organisms, decreasing the likelihood of recurrence, shortening the time to infection resolution, restoring anatomy and function, and minimizing the risk of intraabdominal hypertension/abdominal compartment syndrome $[1,24,25]$. Treatment of intra-abdominal infections typically consists of a combination of antimicrobial agents, surgery, and resuscitation. Antibiotics are selected empirically based on anticipated pathogens, and therapy should be initiated as soon as possible and maintained until resolution of clinical symptoms. Surgical interventions consist of abscess drainage, debridement, and source control. Although debridement is a standard component of surgical intervention, evidence of its benefit is lacking. Fluid resuscitation is typically initiated following general surgical resuscitation. Administering antibiotic therapy following initiation of fluid resuscitation restores adequate visceral perfusion, leading to better drug penetration $[1,11,24,26,27]$.

The Surgical Infection Society (SIS) [28,29] and the Infectious Diseases Society of America (IDSA) published guidelines in 2002 and 2003 for the selection of antiinfective agents to treat cIAIs in adults. These guidelines provide evidence-based recommendations for the treatment of cIAI. The IDSA guidelines were endorsed by the SIS, American Society for Microbiology, and Society of Infectious Disease Pharmacists [1]. Treatment should consider the location of infection and pathogens associated with those anatomical areas. For patients with bowel injuries due to penetrating, blunt, or iatrogenic trauma that had been repaired within $12 \mathrm{~h}$ but have intraoperative contamination by enteric material, the guidelines recommend no more than $24 \mathrm{~h}$ of antimicrobial therapy. Prophylactic therapy is warranted for patients with acute perforations of the stomach, duodenum, and proximal jejunum who have not received antacid therapy or do not suffer from malignancy. Prophylactic therapy is also recommended for patients with acute appendicitis without evidence of gangrene, perforation, abscess, or peritonitis. Patients with acute cholecystitis should be prescribed an antimicrobial if infection is suspected.

Updated guidelines were published by SIS and IDSA in $2010[30,31]$. In the update, distinction is made between community-acquired and health care-acquired cIAIs, and between low- and high-risk patients among the former (the latter are all considered high-risk). Additionally, certain agents (e.g., ampicillin-sulbactam, cefotetan) were deleted 
owing to increasing resistance among Enterobacteriaceae and $B$. fragilis group pathogens, respectively, whereas other agents introduced since the last iteration were added (e.g., doripenem, moxifloxacin).

Both the original and updated SIS and IDSA guidelines recommend that the antibiotics used for empirical treatment of community-acquired intraabdominal infections should be active against gram-negative aerobic and facultative bacilli, as well as $\beta$-lactam-susceptible gram-positive cocci. The guidelines recommend agents with a narrow spectrum of activity in low-risk community-acquired infections. They caution that agents with broader gram-negative coverage may contribute to the emergence of resistance, in the absence of antimicrobial stewardship. Patients with more severe infections, and those with immunosuppression, may benefit from agents with a broad spectrum of activity.

"Appropriate" initial parenteral empiric antimicrobial therapy in patients with community-acquired IAIs requiring surgery is associated with improved clinical outcomes and reduced length of hospital stays. Initial empiric antimicrobial therapy was deemed "appropriate" if all bacterial isolates were sensitive to at least one of the drugs administered [30]. Thus, knowledge of regional microbiologic profiles of community-acquired and nosocomial intraabdominal infections is important to initiate appropriate empiric antimicrobial therapy for cIAI treatment [33-35].

\section{The Role of Fluoroquinolone Antibiotic Therapy in the Management of clAls}

Fluoroquinolones are associated with high potency, a broad spectrum of activity, relative tolerability, and ease of use and administration [7]. Fluoroquinolones (with and without metronidazole) have become the most commonly prescribed antibiotic in the United States for the treatment of intraabdominal infections [36]. The treatment guidelines do updated address the role of fluoroquinolones and that of specific fluoroquinolone agents [1].

The 2003 IDSA guidelines recommend a fluoroquinolone (ciprofloxacin, levofloxacin, gatifloxacin, or moxifloxacin) plus metronidazole for the treatment of mild to moderate cIAIs, and ciprofloxacin plus metronidazole for severe cIAIs. However, two important changes occurred with respect to quinolones since the 2003 guidelines were published: Gatifloxacin was withdrawn from the market because of safety concerns, and moxifloxacin gained U.S. Food and Drug Administration (FDA) approval as monotherapy for mild to moderate cIAIs.

Earlier-generation fluoroquinolones, including ciprofloxacin and levofloxacin, are effective against gram-negative pathogens and require combination therapy with agents such as metronidazole to provide adequate gram-positive and anaerobic coverage. It should be noted that levofloxacin is not approved by the FDA for the treatment of cIAI, even though it is used widely in the community for that indication, commonly as a therapeutic substitute for ciprofloxacin. Anaerobic coverage is essential in the treatment of cIAIs; moxifloxacins, have a broad spectrum of coverage that includes gramnegative, gram-positive, and anaerobic pathogens [37-42].

\section{Moxifloxacin in clAls}

The bactericidal action of moxifloxacin results from the inhibition of type II topoisomerases, deoxyribonucleic acid gyrase and topoisomerase IV, which are required for bacterial deoxyribonucleic acid replication, transcription, repair, and recombination. In contrast to ciprofloxacin, moxifloxacin has good in vitro activity against anaerobes, which enhances its ability to treat mixed aerobic/anaerobic infections [43]. Overall, Goldstein et al. [42] found that $83 \%$ (763 of 923) of anaerobes isolated from patients with cIAI were susceptible to moxifloxacin at a minimum inhibitory concentration (MIC) of $\leq 2 \mathrm{mcg} / \mathrm{mL}$.

The efficacy of moxifloxacin in the treatment of experimental intraabdominal abscesses induced by $B$. fragilis in a murine model was equivalent to clindamycin and higher than metronidazole (cure rates: $57 \%$ for metronidazole, $73 \%$ for moxifloxacin, and $79 \%$ s for clindamycin) [44]. Similarly, moxifloxacin was as effective as imipenem-cilastatin in reducing the mortality rate of mice infected with strains of $B$. fragilis and E. coli [45]. As increasing trends in antimicrobial resistance among clinically important anaerobes and $B$. fragilis isolates have been reported, it is important to assess anaerobic susceptibilities in patients with serious infections if possible [46]. A recent summary presented key data used by the Clinical and Laboratory Standards Institute to determine that moxifloxacin anaerobic breakpoints are $\leq 2 \mathrm{mcg} / \mathrm{mL}$ (susceptible), $4 \mathrm{mcg} / \mathrm{mL}$ (intermediate), and $\geq 8 \mathrm{mcg} / \mathrm{mL}$ (resistant) [47]. Another study, using an ex vivo pharmacodynamic model and done after the breakpoints were established, documented that single doses of both moxifloxacin and levofloxacin administered to normal human volunteers provided bacterial titers $(\geq 1: 2)$ in serum for a prolonged period of time against common aerobic and anaerobic pathogens associated with cIAIs [48].

\section{Pharmacokinetic/pharmacodynamics considerations}

Fluoroquinolones share similar mechanisms of action; nevertheless, there are important differences in their pharmacokinetics (PK) and pharmacodynamics. Moxifloxacin and levofloxacin, for example, have demonstrated comparable PK performance in healthy volunteers and have relatively greater bioavailabilities, longer half-lives, and higher free-drug peak concentration $\left(C_{\max }\right)$ values than ciprofloxacin [48].

Drug penetration into abdominal tissue is an important consideration in IAIs. Moxifloxacin had high penetration and accumulation into the mucosa of the stomach, small bowel, and colon in preoperative patients awaiting gastrointestinal surgery [50]. Tissue concentrations were $10.9 \pm 5.1 \mathrm{mg} / \mathrm{kg}$ in the gastric mucosa, $5.4 \pm 0.5 \mathrm{mg} / \mathrm{kg}$ in small bowel, and $7.8 \pm 7.1 \mathrm{mg} / \mathrm{kg}$ (intravenous [IV]) and $6.6 \pm 3.6 \mathrm{mg} / \mathrm{kg}$ (oral) in the colon. Moxifloxacin concentrations achieved in abdominal tissue, abdominal exudate, and abscess fluid are shown in Table 2 [50]. These tissue concentrations were above the $\mathrm{MIC}_{90}$ for key pathogens commonly encountered in cIAIs (e.g., E. coli and B. fragilis).

In an in vitro study, moxifloxacin was shown to penetrate and accumulate in abdominal abscess fluid and peritoneal exudate in patients with peritonitis [51]. Stass et al. [51] found that administration of a single IV dose of moxifloxacin $400 \mathrm{mg}$ led to moxifloxacin concentrations in peritoneal exudate that exceeded the MICs against key pathogens in patients with peritonitis. Concentrations in the peritoneal exudate reached a geometric mean of $3.32 \mathrm{mg} / \mathrm{L}$ at $1 \mathrm{~h}$, were highest at $2 \mathrm{~h}$ after the start of infusion, and declined to $0.69 \mathrm{mg} / \mathrm{L}$ at $24 \mathrm{~h}$. 
Table 2. Tissue and Serum Moxifloxacin Concentrations in Abdominal Issues

\begin{tabular}{lcc}
\hline Tissue & $\begin{array}{c}\text { Tissue concentration } \\
(\mathrm{mg} / \mathrm{kg})\end{array}$ & $\begin{array}{c}\text { Tissue:serum } \\
\text { ratio }\end{array}$ \\
\hline Stomach & $10.9 \pm 5.1$ & $9.7 \pm 5.7$ \\
Colon IV & $7.8 \pm 7.1$ & $6.8 \pm 3.9$ \\
Colon oral & $6.6 \pm 3.6$ & $5.8 \pm 3.4$ \\
Small bowel & $5.4 \pm 0.5$ & $2.0 \pm 1.6$ \\
\hline
\end{tabular}

All data are presented as mean \pm standard error of the mean. Adapted from Wirtz et al. [50].

$\mathrm{IV}=$ intravenous

Concentrations in pancreatic tissue for a single oral or IV $400 \mathrm{mg}$ dose of moxifloxacin exceeded $\mathrm{MIC}_{90}$ for relevant pathogens [52]. Mean moxifloxacin concentrations in that study were $3.1 \pm 0.9$ and $2.7 \pm 1.4 \mathrm{mg} / \mathrm{kg}$ at $3-3.7 \mathrm{~h}$ post-dose and $3.6 \pm 1.5$ and $3.1 \pm 1.8 \mathrm{mg} / \mathrm{kg}$ at $4.3-5.3 \mathrm{~h}$ post-dose. Studies have also shown accumulation of moxifloxacin in phagocytic and nonphagocytic leukocytes, demonstrating killing of pathogens that may survive inside phagocytic and non-phagocytic leucocytes [53,54].

Another study examined the penetration of moxifloxacin into intraabdominal abscess fluid in a non-randomized, open-label, single-center trial [55]. A single $400 \mathrm{mg}$ dose of moxifloxacin was administered to each of eight patients with CT or ultrasound evidence of a localized intraabdominal abscess requiring interventional drainage but without signs of generalized peritonitis. The abscess fluid:plasma concentration increased continuously from 0.083 (95\% CI: 0.047, 0.147 ) at $2 \mathrm{~h}$ after administration to 1.660 (95\% CI: 0.935, $2.946)$ at $24 \mathrm{~h}$; concentrations in abscess fluid tended to exceed those in plasma after $12-24 \mathrm{~h}$. Half-life and mean residence time were longer in abscess fluid than in plasma, suggesting that moxifloxacin accumulates in abscess fluid. The abscess fluid:plasma concentration continued to increase throughout the 24-h sampling period. High intersubject variability for total moxifloxacin concentrations in intraabdominal abscess fluid was noted, suggesting that abscess wall permeability is likely the parameter most strongly influencing moxifloxacin PK in abscess fluid. Comparison with data obtained from other in vitro studies suggests that abscess fluid concentrations above the MICs for common pathogens seen in intra-abdominal infection were maintained for approximately $8 \mathrm{~h}$ after administration. However, the confirmation of high concentrations of moxifloxacin in abscesses may not equate to efficacy. However clinical efficacy of moxifloxacin and other quinolones in the treatment of abscesses in a number of locations has been confirmed [56-59].

The 24- $\mathrm{h}$ area under the curve $(0-24 \mathrm{~h})$ and the area under the curve:MIC $(50 \%, 90 \%)$ ratio are good pharmacodynamic predictors of antibacterial activities because of the concentration-dependent killing effects of fluoroquinolones [60-62]. An in vitro study demonstrated that moxifloxacin has activity equivalent to levofloxacin plus metronidazole against $E$. coli and B. fragilis [63]. Furthermore, time-kill curves for the combination regimen indicated that levofloxacin was responsible for killing $E$. coli, whereas metronidazole was responsible for killing $B$. fragilis. In another study, moxifloxacin exhibited good antimicrobial activity against most aerobic $(90.8 \%)$ and anaerobic $(97.1 \%)$ pathogens, and moxi- floxacin activity against aerobic organisms exceeded the activities of either levofloxacin and ciprofloxacin [41]. Moxifloxacin is available in both oral and IV formulations at the same dosage ( $400 \mathrm{mg}$ administered once daily), providing flexibility to shift from the parenteral to oral route of administration.

\section{Clinical Evidence in cIAl Patients}

Malangoni et al. conducted a randomized, double-blind, multicenter, comparative trial in adults with a cIAI who were randomly assigned to receive sequential IV/oral moxifloxacin $(400 \mathrm{mg} /$ day) or the combination of IV piperacillin-tazobactam (3.0/0.375 g every $6 \mathrm{~h}$ ), followed by oral amoxicillin-clavulanic acid (800/114 mg every $12 \mathrm{~h}$ ), each for 5-14 days [64]. Overall clinical cure rates at the test-of-cure (TOC) visit (25-50 days posttherapy) for the efficacy-valid population was $80 \%(146 / 183)$ for moxifloxacin and $78 \%(153 / 196)$ for the piperacillintazobactam followed by amoxicillin-clavulanic acid regimen (95\% CI: 7.4-9.3). Table 3 presents the clinical cure rates according to infection type [64].

For hospital-acquired cIAIs, the percentage of patients who had treatment success at TOC was significantly higher with moxifloxacin than the comparator $(82 \%$ vs. $55 \%$; $\mathrm{p}=0.05)$. Overall bacteriological eradication rates were $78 \%(117 / 150)$ with moxifloxacin and $77 \%(126 / 163)$ with the comparator (95\% CI: $-9.9,8.7)$. The most frequently isolated organisms were E. coli, B. fragilis, Streptococcus anginosus, B.thetaiotaomicron, and Pseudomonas aeruginosa. Table 4 presents the bacteriological eradication rates for each pathogen [62]. Although not specifically evaluated in the study of Malangoni et al. the observed bacteriological eradication rates for B. fragilis suggest that moxifloxacin may have clinical value in the treatment of this most common diverticulitis pathogen [65].

A randomized, open, international, multicenter study of adults with cIAI compared the efficacy and safety of sequential IV to oral moxifloxacin ( $400 \mathrm{mg}$ once daily) to that of IV ceftriaxone ( $2 \mathrm{~g}$ once daily) plus metronidazole $(500 \mathrm{mg}$ three times daily), followed by oral amoxicillin/clavulanic acid (625 mg three times daily) [66]. The primary efficacy variable was clinical cure at TOC (days 28-42 after study entry) in the per-protocol population. Of 595 patients in the study, 511 patients were valid for per-protocol analysis (246 moxifloxacin, 265 ceftriaxone/metronidazole). Sequential moxifloxacin was non-inferior to the comparator regimen-clinical cure rates at TOC were $80.9 \%$ versus $82.3 \%$ (moxifloxacin vs. ceftriaxone+metronidazole; $95 \% \mathrm{CI}:-8.9,4.2)$. The incidence of adverse events was comparable between the two treatment groups. Therefore, sequential moxifloxacin monotherapy is as effective and safe as combination therapy with IV ceftriaxone plus IV metronidazole followed by oral amoxicillin/ clavulanic acid for the treatment of cIAI.

\section{Safety of Moxifloxacin in the Treatment of clAls}

Although other fluoroquinolones have established efficacy in earlier studies (e.g., ciprofloxacin when combined with metronidazole), safety issues have complicated their use for cIAI. The Malangoni et al. study, however, demonstrated safety and tolerability profile for moxifloxacin that is equivalent to the comparator regimen in patients with cIAIs. The most common adverse events reported were nausea, hypokalemia, abdominal pain, and constipation, with the rates of 
Table 3. Clinical Cure Rates by Infection Type at Test-of-Cure for the Efficacy-Valid Population

\begin{tabular}{lcccc}
\hline & \multicolumn{3}{c}{ Clinical cure rate $[n / N(\%)]$} \\
\cline { 2 - 5 } Infection type & Moxifloxacin ${ }^{\mathrm{a}}$ & Comparator $^{\mathrm{b}}$ \\
\hline Hospital-acquired cIAIs (total) & $22 / 27$ & $(82)$ & $17 / 31$ & $(55)$ \\
Mild-to-moderate intensity & $16 / 19$ & $(84)$ & $12 / 23$ & $(52)$ \\
Severe intensity & $6 / 8$ & $(75)$ & $5 / 8$ & $(63)$ \\
Community-acquired cIAIs (total) & $124 / 156$ & $(80)$ & $136 / 165$ & $(82)$ \\
Mild-to-moderate intensity & $96 / 119$ & $(81)$ & $117 / 138$ & $(85)$ \\
Severe intensity & $28 / 37$ & $(75)$ & $19 / 27$ & $(70)$
\end{tabular}

Adapted from Malangoni et al. [64].

${ }^{a}$ Moxifloxacin: sequential IV/oral $400 \mathrm{mg} /$ day.

${ }^{\mathrm{b}}$ Comparator: IV piperacillin-tazobactam $(3.0 / 0.375 \mathrm{~g}$ every $6 \mathrm{~h})$, followed by oral amoxicillin-clavulanic acid (800/114 mg every $12 \mathrm{~h}$ ).

$\mathrm{IV}=$ intravenous; $\mathrm{n} / \mathrm{N}=$ number of patients cured/total number with infection; cIAIs $=$ complicated intra-abdominal infections.

adverse events similar for both treatment regimens. A total of 13 deaths were reported in the study (six in the moxifloxacin group and seven in the comparator group), although none were related to the study drug [65]. The recommended dosage of moxifloxacin ( $400 \mathrm{mg}$ IV or oral) remains the same for all approved indications and does not require dosage adjustments per indication or route of administration (i.e., oral or IV) [67]. In patients with abnormal renal function, including those with moderate-to-severe renal insufficiency or complete renal failure on dialysis, moxifloxacin does not require dosage adjustment [67].

\section{Concerns Regarding Clostridium difficile-Associated Diarrhea}

Risk factors for Clostridium difficile-associated diarrhea (CDAD) include antimicrobial exposure, advanced age, hospitalization or long-term care facility exposure, immunosup-

TABle 4. BACteriological ERAdication Rates at the Test-of-Cure Visit for Microbiologically VAlid PATIENTs

\begin{tabular}{lrr}
\hline & \multicolumn{2}{c}{ Bacteriologic eradication $[\mathrm{n} / \mathrm{N}(\%)]$} \\
\cline { 2 - 3 } & $\begin{array}{c}\text { Moxifloxacin } \\
(150 \text { patients })\end{array}$ & $\begin{array}{c}\text { Comparator } \\
(163 \text { patients })\end{array}$ \\
Organism & & \\
\hline Gram-positive aerobes & $25 / 34(74)$ & $39 / 48(81)$ \\
$\quad$ Streptococcus anginosus & $18 / 30(60)$ & $10 / 15(67)$ \\
Streptococcus constellatus & $8 / 11(73)$ & $8 / 15(53)$ \\
Enterococcus faecalis & $13 / 14(93)$ & $9 / 13(69)$ \\
Enterococcus avium & & \\
Gram-negative aerobes & $67 / 87(77)$ & $69 / 90(77)$ \\
Escherichia coli & $9 / 15(60)$ & $14 / 24(58)$ \\
Klebsiella pneumoniae & $18 / 23(78)$ & $14 / 22(64)$ \\
Pseudomonas aeruginosa & & \\
Gram-negative anaerobes & $35 / 41(85)$ & $36 / 50(72)$ \\
Bacteroides fragilis & $29 / 36(81)$ & $27 / 38(71)$ \\
Bacteroides thetaiotaomicron & $9 / 12(75)$ \\
Bacteroides uniformis & $12 / 14(86)$ & 9 \\
\hline
\end{tabular}

Adapted from Malangoni et al. [64].

${ }^{\text {a Organisms with }}>10$ isolates in each treatment arm.

$\mathrm{n} / \mathrm{N}=$ number eradicated/total number of isolates, including eradication and presumed eradication. pression, gastrointestinal surgery, feeding tube, and increased gastric $\mathrm{pH}$ (proton pump inhibitor exposure) [68,69]. Fecaloral transmission through the contaminated hands of health care personnel or the environment has been identified as the primary mode of transmission. Fluoroquinolone resistance was identified in a strain of $C$. difficile following institutional outbreaks of nosocomial diarrhea, leading to reports that fluoroquinolones are associated with the development of CDAD [70]. The epidemic North American pulsed-field gel electrophorsis (NAP)-1 strain of $C$. difficile has been reported to be more virulent than non-epidemic strains and could lead to changes in the epidemiology of CDAD in the United States $[71,72]$. Although the emergence of this strain has been associated with increased toxin production and a demonstrated resistance to fluoroquinolone therapy, this risk has been shown to be mitigated with appropriate infection control practices, including optimal hand hygiene, emphasis on environmental cleaning, stress on the role of antimicrobial stewardship, and use of vancomycin or, in some cases, metronidazole in patients with severe infections [73,74].

To address the relationship between colitis or CDAD and the use of fluoroquinolones, a retrospective analysis was conducted using data from 48 phase II and phase III studies that included a total of 21,355 patients on moxifloxacin. The authors concluded that the incidence of either colitis or CDAD among fluoroquinolone-treated patients was no greater than that observed following non-fluoroquinolone therapies [75]. Further evidence comes from the Malangoni et al. study, in which diarrhea was reported in a small percentage of treated patients (5\% moxifloxacin, $8 \%$ comparator) [64].

\section{Concerns Regarding Anaerobic Resistance}

A recent national survey on the susceptibility of $B$. fragilis isolates $(n=5,225$ from 10 medical centers in the United States) from 1997 to 2004 documented increasing rates of resistance to some antibiotics over the eight-year study period [76]. The rate of resistance to moxifloxacin of $B$. vulgats was very high (MIC range: $38 \%-66 \%$ ). B. fragilis, B. ovatus, $B$. distasonis, and other Bacteroides spp. exhibited significant increases in the rates of resistance to moxifloxacin over the eight years. A previous publication postulated that the emergence of fluoroquinolone resistance among the Bacteroides species may be related to increasing fluoroquinolone use [77]. Conflicting results have been reported, however, with some studies reporting similar findings [78-80] and other studies documenting lower rates of resistance to moxifloxacin [40]. Goldstein et al. [40] found that 83\% (763 of 923) of anaerobes isolated from patients with cIAI were susceptible to moxifloxacin at an MIC of $\leq 2 \mathrm{mcg} / \mathrm{mL}$. No specific information is available in these studies regarding whether these isolates were obtained from patients with health care-associated infections or previous antimicrobial exposure. Based on these data, it is important for each physician to examine anaerobic resistance rates to quinolones and other antimicrobials in their hospital and community when selecting empiric antimicrobials for the treatment of cIAI.

\section{Conclusions}

Clinical data are now available on the efficacy and safety of moxifloxacin for the treatment of cIAIs, including diverticulitis with complications and perforated appendicitis with 
or without abscess, and have been incorporated into updated treatment guidelines based on FDA approval of moxifloxacin as monotherapy for these infections.

Moxifloxacin has good penetration into peritoneal, gastrointestinal, and pancreatic tissue and has demonstrated activity equivalent to that of levofloxacin plus metronidazole combination therapy in cIAIs. Moxifloxacin has a convenient once-daily dosage regimen for all indications and is an important therapeutic option for patients allergic to penicillin or $\beta$-lactams. Further, moxifloxacin does not require a dosage adjustment in patients with abnormal renal function. Moxifloxacin clinical data demonstrate adverse events that are comparable in frequency and intensity with those reported with standard therapies used in the treatment of cIAI. Thus, moxifloxacin provides clinicians with a monotherapy option for the treatment of these common infections.

\section{Acknowledgments}

The authors acknowledge the editorial assistance of ChingLing Chen, Ph.D., in the preparation of this manuscript. Support for this assistance was provided by Schering-Plough Corporation.

\section{Author Disclosure Statement}

This article is based on a roundtable meeting held before the American College of Surgeons Annual Meeting on October 5, 2007, in New Orleans, LA. The roundtable was sponsored by Schering-Plough Corporation.

Dr. W. Cheadle has served on the advisory boards of Merck, Wyeth, Ortho-McNeil, and Schering-Plough; Dr. J.T. Lee and Dr. R.L. Nichols have no financial disclosure; and Dr. L. Napolitano has served on advisory boards of Merck, Wyeth, Ortho-McNeil, Schering-Plough, and Pfizer. The authors accept full responsibility for the construction and authorship of this manuscript.

\section{References}

1. Solomkin JS, Mazuski JE, Baron EJ, et al. Guidelines for the selection of anti-infective agents for complicated intraabdominal infections. Clin Infect Dis 2003;37:997-1005.

2. Liu CD, McFadden DW. Acute abdomen and appendix. In: Surgery: Scientific Principles and Practice, 2nd edition. Greenfield LJ, Mulholland MW, Oldham KT, et al. (eds.). Philadelphia: Lippincott-Raven Publishers, 1997, pp. 1246-1261.

3. Food and Drug Administration. Clinical development and labeling of anti-infective drug products. Available at www .fda.gov/CDER/guidance/infections.htm\#uncomplicated \% 20intra-abdominal\%20infections, accessed June 6, 2008.

4. Mazuski JE, Sawyer RG, Nathens AB, et al. The Surgical Infection Society guidelines on antimicrobial therapy for intra-abdominal infections: An executive summary. Surg Infect 2002;3:161-173.

5. Blot S, De Waele JJ. Critical issues in the clinical management of complicated intra-abdominal infections. Drugs 2005; 65:1611-1620.

6. Evans HL, Raymond DP, Pelletier SJ, et al. Diagnosis of intra-abdominal infection in the critically ill patient. Curr Opin Crit Care 2001;7:117-121.

7. Goldstein EJ. Intra-abdominal anaerobic infections: Bacteriology and therapeutic potential of newer antimicrobial carbapenem, fluoroquinolone, and desfluoroquinolone therapeutic agents. Clin Infect Dis 2002;35(suppl 1):S106-S111.

8. Goldstein EJ, Snydman DR. Intra-abdominal infections: Review of the bacteriology, antimicrobial susceptibility and the role of ertapenem in their therapy. J Antimicrob Chemother 2004;53(suppl 2):ii29-ii36.

9. Solomkin JS, Hemsell DL, Sweet R, et al. Evaluation of new anti-infective drugs for the treatment of intraabdominal infections. Infectious Diseases Society of America and the Food and Drug Administration. Clin Infect Dis 1992; 15(suppl 1):S33-S42.

10. Solomkin JS, Goldstein EJC, Stollman NH, et al. The role of moxifloxacin in the management of complicated intraabdominal infections. Infect Dis Clin North Am 2007; 21(suppl 1):16-24.

11. Nathens $A B$, Rotstein OD. Antimicrobial therapy for intraabdominal infection. Am J Surg 1996;172(suppl 6A):1S-6S.

12. Brismar B, Nord CE. Monobactams and carbapenems for treatment of intraabdominal infections. Infection 1999;27: 136-147.

13. Addiss DG, Shaffer N, Fowler BS, Tauxe RV. The epidemiology of appendicitis and appendectomy in the United States. Am J Epidemiol 1990;132:910-925.

14. McCaig LF, Nghi L. National hospital ambulatory medical care survey: 2000 emergency department summary. Advance data. CDC 2002;316:April 22.

15. Graff L, Russell J, Seashore J, et al. False-negative and falsepositive errors in abdominal pain evaluation: Failure to diagnose acute appendicitis and unnecessary surgery. Acad Emerg Med 2000;7:1244-1255.

16. Naoum JJ, Mileski WJ, Daller JA, et al. The use of abdominal computed tomography scan decreases the frequency of misdiagnosis in cases of suspected appendicitis. Am J Surg 2002;184:587-589.

17. Craig S. Appendicitis acute. In: Emedicine From WebMD. Lober W (ed.). Available at www.emedicine.com/emerg/ topic41.htm, accessed September 12, 2007.

18. Huang E. Complications of appendectomy, colon, and rectal surgery. In: Complications in Surgery. Mulholland MW, Doherty GM (eds.). Philadelphia: Lippincott Williams \& Wilkins, 2006, pp. 498-521.

19. Mueller MH, Glatzle J, Kasparek MS, et al. Long-term outcome of conservative treatment in patients with diverticulitis of the sigmoid colon. Eur J Gastroenterol Hepatol 2005;17: 649-654.

20. Parks TG. Natural history of diverticular disease of the colon. Clin Gastroenterol 1975;4:53-69.

21. Kaiser AM, Jiang JK, Lake JP, et al. The management of complicated diverticulitis and the role of computed tomography. Am J Gastroenterol 2005;100:910-917.

22. Dominguez EP, Sweeney JF, Choi YU. Diagnosis and management of diverticulitis and appendicitis. Gastroenterol Clin North Am 2006;35:367-391.

23. Brook I, Frazier EH. Aerobic and anaerobic microbiology of retroperitoneal abscesses. Clin Infect Dis 1998;26:938-941.

24. Schein M. Surgical management of intra-abdominal infection: Is there any evidence? Langenbecks Arch Surg 2002; 387:1-7.

25. van Goor H, Hulsebos RG, Bleichrodt RP. Complications of planned relaparotomy in patients with severe general peritonitis. Eur J Surg 1997;163:61-66.

26. Madan AK. Use of ciprofloxacin in the treatment of hospitalized patients with intra-abdominal infections. Clin Ther 2004;26:1564-1577. 
27. Marshall JC, Innes M. Intensive care unit management of intra-abdominal infection. Crit Care Med 2003;31:2228-2237.

28. Mazuski JE, Sawyer RG, Nathens AB, et al. The SIS guidelines on antimicrobial therapy for intra-abdominal infections: An executive summary. Surg Infect (Larchmt) 2002;3: 161-173.

29. Mazuski JE, Sawyer RG, Nathens AB, et al. The SIS guidelines on antimicrobial therapy for intra-abdominal infections: Evidence for the recommendations. Surg Infect (Larchmt) 2002;3:175-233.

30. Krobot K, Yin D, Zhang Q, et al. Effect of inappropriate initial empiric antibiotic therapy on outcome of patients with community-acquired intra-abdominal infections requiring surgery. Eur J Clin Microbiol Infect Dis 2004; 23:682-687.

31. Solomkin JS, Mazuski JE, Bradley JS, et al. Diagnosis and management of complicated intra-abdominal infection in adults and children: Guidelines by the Surgical Infection Society and the Infectious Diseases Society of America. Surg Infect (Larchmt) 2010;11:79-109.

32. Solomkin JS, Mazuski JE, Bradley JS, et al. Diagnosis and management of complicated intra-abdominal infection in adults and children: Guidelines by the Surgical Infection Society and the Infectious Diseases Society of America. Clin Infect Dis 2010;50:133-164.

33. Montravers P, Lepape A, Dubreuil L, et al. Clinical and microbiological profiles of community-acquired and nosocomial intra-abdominal infections: Results of the French prospective, observational EBIIA study. J Antimicrob Chemother 2009;63:785-794.

34. Baquero F, Hsueh P-R, Bochicchio GV, et al. In vitro susceptibilities of aerobic and facultatively anaerobic gram negative bacilli isolated from patients with IAIs worldwide: 2005 results from SMART. Surg Infect (Larchmt) 2009;10:99_ 104.

35. Rossi F, Baquero F, Hsueh PR, et al. In vitro susceptibilities from SMART-2004. J Antimicrob Chemother 2006;58:205210.

36. Linder JA, Huang ES, Steinman MA, et al. Fluoroquinolone prescribing in the United States: 1995-2002. Am J Med 2005;118:259-268.

37. Citron DM, Appleman MD. Comparative in vitro activities of trovafloxacin (CP-99,219) against 221 aerobic and 217 anaerobic bacteria isolated from patients with intra-abdominal infections. Antimicrob Agents Chemother 1997;41:23122316.

38. Behra-Miellet J, Dubreuil L, Jumas-Bilak E. Antianaerobic activity of moxifloxacin compared with that of ofloxacin, ciprofloxacin, clindamycin, metronidazole and beta-lactams. Int J Antimicrob Agents 2002;20:366-374.

39. Stein GE, Goldstein EJ. Review of the in vitro activity and potential clinical efficacy of levofloxacin in the treatment of anaerobic infections. Anaerobe 2003;9:75-81.

40. Wenzler S, Schmidt-Eisenlohr E, Daschner F. Comparative in vitro activities of three new quinolones and azithromycin against aerobic pathogens causing respiratory tract and abdominal wound infections. Chemotherapy 2004;50:40-42.

41. Edmiston CE, Krepel CJ, Seabrook GR, et al. In vitro activities of moxifloxacin against 900 aerobic and anaerobic surgical isolates from patients with intra-abdominal and diabetic foot infections. Antimicrob Agents Chemother 2004;48:1012-1016.

42. Goldstein EJ, Citron DM, Warren YA, et al. In vitro activity of moxifloxacin against 923 anaerobes isolated from human intra-abdominal infections. Antimicrob Agents Chemother 2006;50:148-155.

43. Stein GE, Goldstein EJC. Fluoroquinolones and anaerobes. Clin Infect Dis 2006;42:1598-1607.

44. Thadepalli H, Chuah SK, Gollapudi S. Therapeutic efficacy of moxifloxacin, a new quinolone, in the treatment of experimental intra-abdominal abscesses induced by Bacteroides fragilis in mice. Chemotherapy 2008;50:76-80.

45. Schaumann R, Blatz R, Beer J, et al. Effect of moxifloxacin versus imipenem/cilastatin treatment on the mortality of mice infected intravenously with different strains of Bacteroides fragilis and Escherichia coli. I Antimicrob Chemother 2004;53:318-324.

46. Liu CY, Huang YT, Liao $\mathrm{CH}$, et al. Increasing trends in antimicrobial resistance among clinically important anaerobes and $B$. fragilis isolates causing nosocomial infections: Emerging resistance to carbapanems. Antimicrob Agents Chemother 2008;52:3161-3168.

47. Ambler J, Rennie R, Poupard J, et al. Determination of moxxifloxacin anaerobic susceptbility breakpoints according to the CLSI guidelines. Diagn Microbiol Infect Dis 2008;61: 49-57.

48. Stein GE, Schooley S, Tyrrell KL, et al. Serum bactericidal activities of moxifloxacin and levofloxacin against aerobic and anaerobic intra-abdominal pathogens. Anaerobe 2008; 14:8-12.

49. Lubasch A, Keller I, Borner K, et al. Comparative pharmacokinetics of ciprofloxacin, gatifloxacin, grepafloxacin, levofloxacin, trovafloxacin, and moxifloxacin after single oral administration in healthy volunteers. Antimicrob Agents Chemother 2000;44:2600-2603.

50. Wirtz M, Kleeff J, Swoboda S, et al. Moxifloxacin penetration into human gastrointestinal tissues. I Antimicrob Chemother 2004;53:875-877.

51. Stass H, Rink AD, Delesen $H$, et al. Pharmacokinetics and peritoneal penetration of moxifloxacin in peritonitis. I Antimicrob Chemother 2006;58:693-696.

52. Wacke R, Forster $S$, Adam U, et al. Penetration of moxifloxacin into the human pancreas following a single intravenous or oral dose. J Antimicrob Chemother 2006;58: 994-999.

53. Mandell GL, Coleman E. Uptake, transport, and delivery of antimicrobial agents by human polymorphonuclear neutrophils. Antimicrob Agents Chemother 2001;45:1794-1798.

54. Pascual A, Garcia I, Ballesta S, Perea EJ. Uptake and intracellular activity of moxifloxacin in human neutrophils and tissue-cultured epithelial cells. Antimicrob Agents Chemother 1999;43:12-15.

55. Rink AD, Stass H, Delesen H, et al. Pharmacokinetics and tissue penetration of moxifloxacin in intervention therapy for intra-abdominal abscess. Clin Drug Investig 2008;28: 71-79.

56. Solomkin J, Zhao YP, Ma El, et al. DRAGON study team. Moxifloxacin is non-inferior to combination therapy with ceftriaxone plus metronidazole in patients with communityorigin complicated intra-abdominal infections. Int J Antimicrob Agents 2009;34:439-445.

57. Fihman V, Bercot B, Mateo J, et al. First successful treatment of Nocardia farcinica brain abscess with moxifloxacin. J Infect 2006;52:99-102.

58. Shapiro MA, Sesnie JC, Desaty TM, et al. Comparative therapeutic efficacy of clinafloxacin in a Pseudomonas aeruginosa mouse renal abscess model. J Antimicrob Chemother 1998;41:403-405. 
59. Ott SR, Allewelt M, Lorenz J, et al. German Lung Abscess Study Group. Moxifloxacin vs. ampicillin/sulbactam in aspiration pneumonia and primary lung abscess. Infection 2008;36:23-30.

60. Stass H, Kubitza D. Pharmacokinetics and elimination of moxifloxacin after oral and intravenous administration in man. J Antimicrob Chemother 1999;43(suppl B):83-90.

61. Sullivan JT, Lettieri JT, Liu P, Heller AH. The influence of age and gender on the pharmacokinetics of moxifloxacin. Clin Pharmacokinet 2001;40(suppl 1):11-18.

62. Wispelwey B. Clinical implications of pharmacokinetics and pharmacodynamics of fluoroquinolones. Clin Infect Dis 2005;41(suppl 2):S127-S135.

63. Hermsen ED, Hovde LB, Sprandel KA, et al. Levofloxacin plus metronidazole administered once daily versus moxifloxacin monotherapy against a mixed infection of Escherichia coli and Bacteroides fragilis in an in vitro pharmacodynamic model. Antimicrob Agents Chemother 2005;49:685-689.

64. Malangoni MA, Song J, Herrington J, et al. Randomized controlled trial of moxifloxacin compared with piperacillintazobactam and amoxicillin-clavulanate for the treatment of complicated intra-abdominal infections. Ann Surg 2006; 244:204-211.

65. Brook I, Frazier EH. Aerobic and anaerobic microbiology in intra-abdominal infections associated with diverticulitis. J Med Microbiol 2000;49:827-830.

66. Weiss G, Reimnitz P, Hampel B, et al. AIDA Study Group. Moxifloxacin for the treatment of patients with cIAI, the AIDA study. J Chemother 2009;21:170-180.

67. Moxifloxacin [package insert]. Kenilworth, NJ: ScheringPlough Corporation, 2007.

68. Bartlett JG. Clinical practice. Antibiotic-associated diarrhea. N Engl J Med 2002;346:334-339.

69. Owens RC. Clostridium difficile-associated disease: Changing epidemiology and implications for management. Drugs 2007;67:487-502.

70. Johnson S, Samore MH, Farrow KA, et al. Epidemics of diarrhea caused by a clindamycin-resistant strain of Clostridium difficile in four hospitals. N Engl J Med 1999;341: 1645-1651.

71. Hubert B, Loo VG, Bourgault AM, et al. A portrait of the geographic dissemination of the Clostridium difficile North American pulsed-field type 1 strain and the epidemiology of C. difficile-associated disease in Québec. Clin Infect Dis 2007;44:238-244.

72. Warny M, Pepin J, Fang A, et al. Toxin production by an emerging strain of Clostridium difficile associated with out- breaks of severe disease in North America and Europe. Lancet 2005;366:1079-1084.

73. Loo VG, Poirier L, Miller MA, et al. A predominantly clonal multi-institutional outbreak of Clostridium difficile-associated diarrhea with high morbidity and mortality. N Engl J Med 2005;353:2442-2449.

74. Institut National de Santé Publique du Québec. Surveillance des diarrhées associées à Clostridium difficile au Québec. Bilan du 21 août 2005 au 19 août 2006. Available at www .inspq.qc.ca/pdf/publications/561-SurveillanceCDifficileAout2005-aout2006.pdf, accessed January 7, 2007.

75. Owens RC, Kruesmann F, Reiter C, et al. Comparative frequency of Clostridium difficile-associated diarrhea in Phase II and Phase III moxifloxacin clinical trials [poster 117]. Poster presented at the 7th European Congress of Chemotherapy and Infection, October 19-22, 2005, Florence, Italy.

76. Snydman DR, Jacobus NV, McDermott LA, et al. National survey on the susceptibility of Bacteroides fragilis group: Report and analysis of trends in the United States from 1997 to 2004. Antimicrob Agents Chemother 2007;51:1649-1655.

77. Golan YL, McDermott A, Jacobus NV, et al. Emergence of fluoroquinolone resistance among the Bacteroides species. J Antimicrob Chemother 2003;52:208-213.

78. Betriu C, Rodriguez-Avial I, Gomez M, et al. Changing patterns of fluoroquinolone resistance among Bacteroides fragilis group organisms over a 6-year period (1997-2002). Diagn Microbiol Infect Dis 2005;53:221-223.

79. Oteo-Iglesias J, Alos JI, Gomez-Garces JL. Increase in resistance to new fluoroquinolones from 1998 to 2001 in the Bacteroides fragilis group. I Antimicrob Chemother 2002;50: 1055-1057.

80. Papaparaskevas J, Pantazatou A, Katsandri A, et al. Moxifloxacin resistance is prevalent among Bacteroides and Prevotella species in Greece. J Antimicrob Chemother 2008;62: 137-141.

Address correspondence to: Dr. Lena M. Napolitano Acute Care Surgery (Trauma, Burn, Critical Care, Emergency Surgery) Department of Surgery University of Michigan Health Systems 1500 E. Medical Center Dr. 1C421 UH SPC 5033 Ann Arbor, MI 48109-5033

E-mail: lenan@umich.edu 